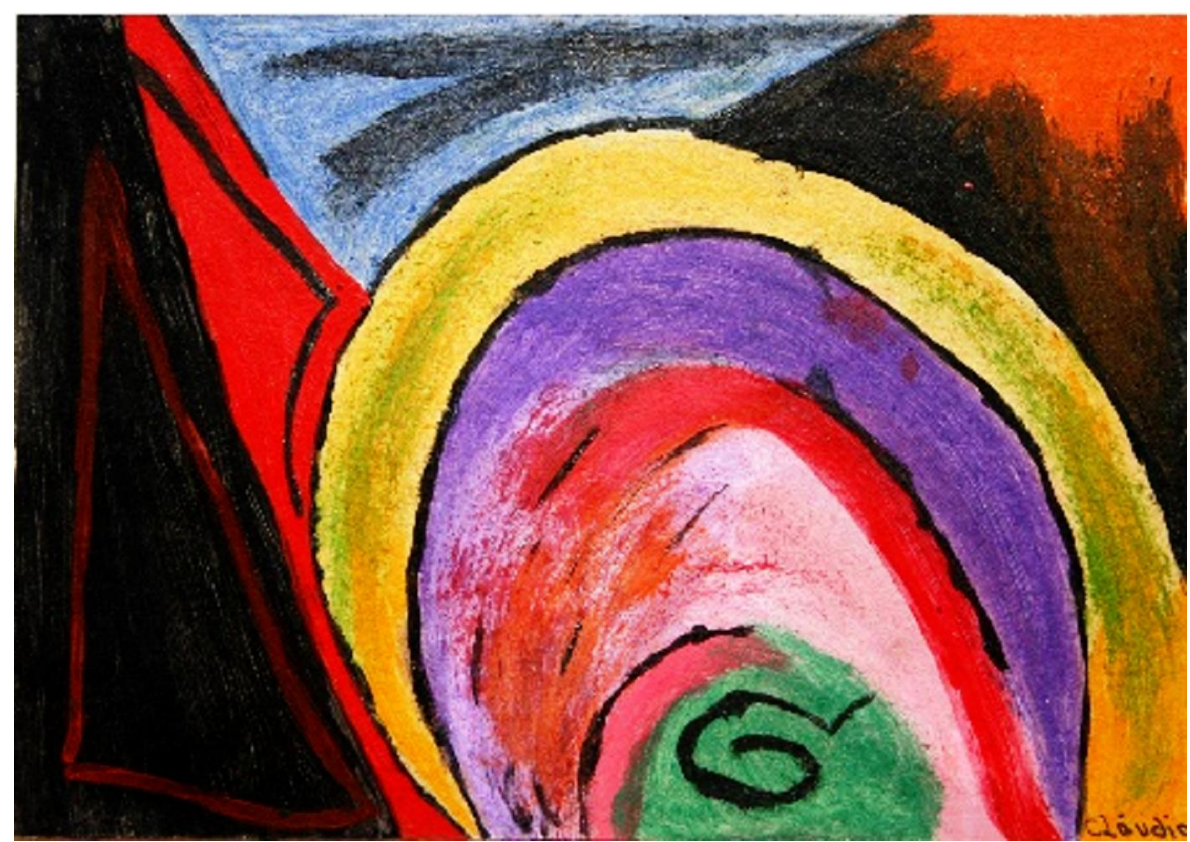

Cláudia Lins

\title{
Leituras polonesas da Literatura Brasileira
}

\section{Zbigniew Wódkowski}

\section{Por Maria Antonieta Pereira}

Zbigniew Wódkowski é filólogo, com especialização em Língua Portuguesa, professor de Literatura Comparada, tradutor e doutor pela Université de Montréal. Foi professor no Departamento da Língua e Cultura Portuguesa e Brasileira da Universidade de Varsóvia e no Departamento da Literatura Comparada da Université de Montréal. Ex-bolsista do Instituto Camões e da Fundação Calouste Gulbenkian, em Lisboa. Atualmente, é professor de inglês em Ottawa. Em polaco, publicou Modernidade e pós-modernidade na literatura de viagens de Bruce Chatwin e tem no prelo Um carisma que nunca termina: Malcolm Lowry e a questão de autocriação nas suas cartas. Atualmente, está traduzindo, para o polaco, autores como Fernando Pessoa, Guimarões Rosa e Clarice Lispector. Contato: zwodesympatico.ca

Maria Antonieta Pereira é professora aposentada de Teoria da Literatura e Literatura Comparada na Faculdade de Letras/UFMG, onde atualmente exerce trabalho voluntário na Graduação e na Pós-Graduação. Pós-doutora pela Universidad de Buenos Aires. 
Pesquisadora convidada pela "Canada Research Chair in Literay and Cultural Transfers", Universidade de Ottawa, Canadá. Autora de vários livros e artigos sobre telas, textos e educação. Pesquisa atual: Esquecer para lembrar - redes narrativas na cibercultura. Fundadora do Programa de Ensino, Pesquisa e Extensão A tela e o texto e membro de sua Coordenação Geral.

\section{Maria Antonieta Pereira/Revista txt - Como e quando você estabeleceu contato com a Literatura Brasileira?}

Sobre isso, é interessante dizer que o Brasil ocupa um lugar particular no imaginário coletivo polaco. Cada criança da escola primária, pelo menos as da minha geração, tinha que ler como leitura obrigatória um longo e chato poema intitulado o Senhor Balcer no Brasil, de 1910. Esse poema narra uma viagem transatlântica dos camponeses polacos em busca do pão e da "terra prometida" no Brasil. Em vez de encontrarem, naquele país, o "paraíso" com que tanto tinham sonhado, os emigrantes tinham que se confrontar com uma natureza hostil, animais salvagens e alienação lingüística. Nessas circunstâncias, toda essa aventura acabava em desastre. Então como vê, o Brasil ocupa o lugar de uma distopia, de uma utopia negativa no imaginário coletivo polaco. Mas, apesar dessa imagem negativa, - Brasil, como um país geografica e historicamente concreto, tem sempre gozado da simpatia dos polacos. No meu caso, aquele poema despertou em mim um enorme interesse. Aquelas descrições sugestivas sobre a natureza, os animais e as pessoas tornaramse um grande desejo de conhecer melhor aquela terra e aquela gente. Esses sonhos infantis e juvenis foram algumas das razões que me levaram a começar o estudo da Língua Portuguesa. Então, estabeleci um primeiro contato com a Literatura Brasileira quando comecei meus estudos de Língua Portuguesa no Departamento de Língua e Cultura Portuguesa e Brasileira que fazia parte da Cátedra de Estudos Ibéricos da Universidade de Varsóvia. E aqui devo mencionar um nome que desempenhou um papel importante no desenvolvimento de meu interesse pela cultura brasileira. Trata-se da professora Janina Z. Klave, uma pessoa verdadeiramente apaixonada pela cultura e pela literatura brasileira. Foi ela que, em seus cursos sobre a história e a literatura brasileiras, apresentou perante nós um panorama excitante do Brasil, de sua cultura e sua literatura. Foi ela que nos introduziou aos grandes prosadores, poetas e artistas brasileiros. Hoje, ainda me lembro das aulas durante quais escutávamos a música de Villa-Lobos: em seus comentários, ela nos explicava os sons e as imagens do Brasil contidos naquela música. Desde então, Villa-Lobos tem sido meu compositor moderno predileto. Assim foram, grosso modo, meus primeiros contatos com o Brasil e sua cultura. 


\begin{abstract}
Por que você se interessou em traduzir obras da Literatura Brasileira para o polonês? Existe um mercado leitor de Literatura Brasileira na Polônia ou você está contribuindo para criá-lo?
\end{abstract}

Como estudantes no Departamento de Língua e Cultura Portuguesa e Brasileira, inspirados e ajudados pela acima mencionada profa. J. Klave, praticamente a cada ano organizávamos serões de poesia portuguesa, brasileira ou africana de expressão portuguesa, na sede da Sociedade da Amizade Polaco-Brasileira, em Varsóvia. Foi naquele tempo que vim a conhecer "de perto" alguns grandes poetas contemporâneos brasileiros porque nós, estudantes, traduzíamos suas poesias para o polaco. Cada estudante tinha seu poeta para traduzir. Lembro-me que, em um ano, coube-me a tarefa de escolher e traduzir alguns poemas de Carlos Nejar. Quando o li, fiquei deslumbrado. Tinha a impressão de que um profeta do Antigo Testamento falava para mim. De um lado, aquele ritmo, aqueles sons, aquela beleza da simplicidade da língua, de outro, aquele jogo de ambivalências semânticas e uma enorme riqueza de sutis referências intertextuais: fiquei apaixonado por esse poeta. Tenho uma seleção de suas poesias traduzidas para o polaco e espero que, em algum momento, ela veja a luz do dia. É exatamente daquele tempo que data meu interesse por traduzir a Literatura Brasileira para o polaco. E também, naquele tempo, experimentei pela primeira vez o sabor da caipirinha. Após o serão, sempre tivemos uma recepção durante a qual os estudantes podiam virar um copinho de caipirinha com seus professores.

\title{
Quais foram suas primeiras impressões de leitura de Grande sertão: veredas?
}

Eu li, pela primeira vez, Grande sertão: veredas durante o curso introdutório à Literatura Brasileira que fiz no segundo ano, onde a leitura desse livro foi obrigatória. Naquela altura, eu ainda não sabia suficientemente português para comprender tudo. Penso que compreendi mais ou menos a metade do que li. Após meus estudos, quando já trabalhava como professor assistente no Departamento de Língua e cultura Portuguesa e Brasileira da Universidade de Varsóvia, voltei a Grande sertão: veredas. Li todo o livro mais uma vez e fiquei embriagado sobretudo pela riqueza da língua dessa obra. Quando lia o livro, e traduzia só para mim certas expressões, frases etc., tinha a impressão de que voltava à infância e ouvia minha mãe falar a mim. Pois minha mãe falava um polaco que ninguém mais fala na Polônia de hoje, um polaco cheio de palavras e expressões barrocas e extremamente complexas em suas conotações existenciais, religiosas e sociais. Cada frase dela tinha uma melodia específica para exprimir alegria ou dor, esperança ou medo, recompensa ou castigo etc. E foi 
precisamente isso que me impressionou muito nesse livro: uma humanidade simples em sua superfície, mas que revela uma profunda sabedoria sobre a vida, uma humanidade que tenta explicar as questões existenciais básicas do ser humano e que lida com a questão do bem e do mal. E essa é uma característica de toda obra de arte universal. Para terminar, queria frizar que é precisamente a língua de minha mãe que utilizo em minha tradução para o polaco de Grande sertão: veredas, um projeto que penso terminar daqui a algum tempo. Já existe uma tradução de Grande sertão: veredas para o polaco feita, se não me engano, nos finais dos anos sessenta, mas ela contém certos erros e omissões do texto original.

\section{Você conhece o sertão brasileiro descrito nessa obra? $\mathrm{Na}$ Polônia, existem paisagens geográficas, sociais ou culturais semelhantes ao sertão?}

Não, pessoalmente não conheço o sertão brasileiro. Conheço-o, porém, através de livros, filmes, documentários etc. Penso que seria uma experiência única poder ver pessoalmente aquela paisagem. Estou a imaginar agora - aquela paisagem deve despertar no indivíduo profundas emoções metafísicas. Não, na Polônia não temos paisagens geográficas semelhantes ao sertão brasileiro. No que diz respeito à, digamos, paisagem cultural em sentido amplo, a situação é diferente. Para responder a essa pergunta, vou contar-lhe uma breve história do que me aconteceu há muitos anos. Num verão, em meu tempo de estudante, fomos um grupo de amigos às montanhas para fazer turismo. Um dia, estávamos no alto das montanhas, e pela tarde chovia tanto que não queríamos passar a noite em nossas tendas. Então, fomos à casa de uns montanheses para perguntar se poderíamos pernoitar no celeiro deles. Eram gente simples mas muito hospitaleira. Ofereceram-nos um jantar e depois do jantar, na penumbra do quarto, com velas acesas, porque não havia eletricidade naquele dia, sentados em frente das janelas entreabertas, ouvindo a chuva a bater no telhado e a murmurar nas folhas das árvores, eles se puseram a nos contar histórias. Olhando pelas janelas para os vales lá embaixo, cheios de névoa úmida e com um crepúsculo cada vez mais escuro, eles contaram incríveis histórias fantásticas sobre o diabo. Um diabo que vive nas árvores, um diabo que vive nos poços, um diabo que vem com os raios de sol, um diabo que vem com a chuva, um diabo que possui os animais, um diabo que possui os homens que, em seguida, podem matar outros homes com seu olhar malicioso. Cada diabo tinha um nome próprio. O que me impressionou é que eles contaram aquelas histórias não para nos assustar mas para falar sobre seu mundo cotidiano. Para eles, tudo aquilo era verdade, o diabo fazia parte do mundo real deles. Eles acreditavam naquilo e contando suas histórias juravam que tinham visto o diabo numa ou noutra forma: ora como um animal, ora como um homem ou mesmo como um monstro que 
vinha às escondidas, na noite. E quem eram aqueles montanheses simples? No meu ver, todos eles eram Riobaldos. Essa história que acabo de contar mostra que existe uma semioesfera (Lotman) comum entre várias culturas, que une toda a humanidade.

\section{Atualmente, você está trabalhando também na tradução da obraPaixão segundo G.H., de Clarice Lispector. Como tem sido a recepção da obra dela na Polônia?}

É verdade, atualmente estou trabalhando com A paixão segundo G.H. porque uma editora em Varsóvia está interessada em publicar esse livro. Num futuro mais distante, se possível, vou preparar uma coletânea de contos. Penso que ainda não podemos falar sobre a recepção da obra de Clarice Lispector na Polônia porque, apesar de haver alguns contos dispersos em vários jornais, publicados ao longo de muitos anos, nenhuma obra maior, salvo A hora da estrela, foi publicada na Polônia.

\section{- fato de Clarice Lispector ser de origem ucraniana aproxima sua obra da cultura polonesa? Como tradutor, você identifica na obra da escritora brasileira alguns traços da cultura eslava?}

Essa é uma pergunta interessante. Quando os pais da escritora emigraram da Ucrânia, Clarice Lispector tinha apenas dois meses. Então, além de sua casa, em que dominava, creio eu, um ambiente judaico-eslavo, ela nunca viveu na cultura eslava propriamente dita. Nós, eslavos, somos bastante diversificados em termos de nossa história, cultura, religião, mentalidade etc. Como polaco, posso falar sobre certos aspectos gerais da "alma" polaca, se me permite utilizar aqui esse termo um pouco antiquado, que encontro na obra de C. Lispector. Quando você escuta a música de F. Chopin, que é polaquíssimo tanto em sua obra como em sua vida, logo nota uma tensão entre o lírico e o trágico. E assim são os polacos - ora líricos, ora trágicos. Existe ainda outro aspecto da "alma" polaca que é a ironia uma ironia às vezes muito dolorosa. Com essa ironia, a "alma" polaca esforça-se por se libertar da tensão entre o lírico e o trágico. O melhor exemplo dessa atitude na literatura moderna polaca é Witold Gombrowicz. Praticamente toda a sua obra, tanto novelística como ensaística, é consagrada a essa tentativa de se libertar dessa "polacidade" trágico-lírica. Para mim, foi uma descoberta deslumbrante quando, depois de ter entrado em contato com a MPB (Música Popular Brasileira) e de ter ouvido Carlos Jobim, Vinícius de Morais, Maria Bethânia e muitos outros, notei a presença do lírico e do trágico na música deles. Eu acho que esse é um dos traços comuns de nossas indentidades. Claro que essa analogia é um pouco simplificada, mas deve ser levada em consideração. E agora, onde é que se situa Lispector nesse contexto? Para mim, Lispector é sobretudo uma escritora do insólito; ela 
surpreende o leitor a cada momento, tanto no nível da língua como no nível da matéria narrada. Em suas melhores obras, tais como A paixão segundo G.H., ela viola e destrói as normas estabelecidas e artificias do uso lingüístico e tem muito prazer em fazê-lo. De outro lado, ela procura uma nova ordem lingüística e, para fazê-lo, recorre a grandes formas narrativas, tais como a Bíblia, por exemplo, estabelecendo assim muitas referências intertextuais. Note-se bem que $A$ paixão segundo G.H. começa com este soluço trágico-lírico: "Procuro, procuro..." sua escrita é cheia de inquietude espiritual, mental e intelectual, criada, a meu ver, pela tensão entre o trágico e o lírico. A idée fixe de sua obra é a dialética entre a ausência e a presença. Existe um pequeno texto revelatório de Lispector intitulado "A vitória nossa" que, se analisado sob o ângulo da poética do insólito que inclui a categoria da tensão entre o lírico e o trágico, pode ser considerado o testamento artístico e ideólogico da escritora. Talvez seja por isso que, tendo-o lido há tantos anos, ainda me lembro desse texto e quase poderia recitá-lo de cor. Por quê? Porque existe nele uma sutil intertextualidade com um prática discursiva altamente ritualizada. E assim é Lispector - desconstrói e reconstrói, perde-se no trágico e re-encontra-se a si mesma no lírico. Por isso, como típico polaco trágico-lírico, admiro sua obra.

No Brasil, existe uma teoria da tradução formulada pelo poeta Haroldo de Campos que se chama "transcriação". Essa teoria afirma que não é possível traduzir uma obra sem re-criá-la ou trans-criá-la. Você concorda com essa idéia?

Em polaco, nós temos duas palavras que exprimem a idéia de "traduzir" em português, cuja origem é o latim traducere. Em sua etimologia, a primeira palavra polaca significa mais ou menos "levar uma coisa de um lugar e deixá-la noutro." A segunda palavra significa "explicar uma coisa utilizando outras palavras". Eu me identifico com o sentido dessa segunda palavra. Pelo que sei de alguns escritos teóricos e da prática tradutória de Haroldo de Campos, a teoria da transcriação está mais próxima desse segundo sentido. Agora, se estamos de acordo que uma tradução é uma transcriação ou mesmo uma recriação, muitas perguntas se colocam. A meu ver, a mais importante é: quais são os limites dessa recriação e quanta liberdade temos na transcriação? Para terminar, queria frizar que, em português, há também duas palavras para exprimir o ato de traduzir que são "traduzir" e "verter". Se estudarmos o significado profundo dessas palavras, descobriremos coisas bem interessantes. Penso que as palavras "verter" e "versão" estão muito próximas da teoria de transcriação de Haroldo de Campos.

Como tradutor, quais são as estratégias que você utiliza para dizer em polonês o que foi imaginado em português? 
Tradutore, traditore. Para responder a essa pergunta, vou parafrasear o fomoso poema de Fernando Pessoa: quando traduzo, eu finjo em polaco o que foi imaginado em português. Finjo até um ponto em que não sei se eu realmente traduzo ou se escrevo uma nova obra. Às vezes, precisamos um pouco dessa loucura criativa. Começo a falar como Haroldo de Campos, não é? Mas, a sério, quem poderá me dizer quais estratégias devo utilizar para traduzir "o Deus" lispectoriano para uma língua em que não existe nenhuma concepção do artigo definido ou indefinido? Como sabemos, esse jogo entre "o Deus" e "Deus" em A paixão segundo G.H.tem enormes conseqüências artísticas e ideológicas. Quem poderá me dizer como traduzir para o polaco a palavra "jagunço" sem deturpar suas conotações mundividenciais, sociais, culturais etc.?

\section{Existe alguma obra da Literatura Brasileira que você gostaria de traduzir?}

Claro que existe. Há não somente uma, mas muitas obras da Literatura Brasileira que eu queria verter para o polaco. Um dos escritores que eu gostaria de traduzir é Osman Lins outro gigante da Literatura Brasileira e mundial. E a obra éAvalovara. Penso que estas duas obras - Avalovara e Grande sertão: veredas - completam-se, de certa maneira. Através de sua experimentação formal, Osman Lins alcançou em Avalovara, o que Guimarães Rosa alcançou em Grande sertão: veredas através de seu palpável realismo mágico - levar aos limites a referencialidade e auto-referencialidade da língua. Não sei se é possível escrever algo de novo após eles...

Ottawa, 14 de abril de 2008. 